\begin{tabular}{|l|l|}
\hline Postprint Version & 1.0 \\
\hline Journal website & $\underline{\underline{\text { http://www.journalofclinicalvirology.com/article/S1386-6532(05)00066- }}}$ \\
\hline Pubmed link & $\underline{\underline{\text { http:tract }}}$ \\
\hline DOI & 10.1016 ww.ncbi.nlm.n.nih.gov/pubmed/16157259 \\
\hline
\end{tabular}

\title{
Implementation of the Community Network of Reference Laboratories for Human Influenza in Europe
}

\author{
Adam Meijer ${ }^{\mathrm{a}, \mathrm{b}, *}$, Martine Valette $^{\mathrm{c}}$, Jean-Claude Manuguerra ${ }^{\mathrm{d}}$, Pilar Pérez-Breña ${ }^{\mathrm{e}}$, \\ John Paget ${ }^{\mathrm{a}}$, Caroline Brown ${ }^{\mathrm{a}}$, Koos van der Velden ${ }^{\mathrm{a}, \mathrm{f}}$
}

on behalf of the Virology Working Group of the European Influenza Surveillance Scheme ${ }^{1}$

${ }^{a}$ European Influenza Surveillance Scheme Co-ordination Centre, Netherlands Institute for Health Services Research (NIVEL), P.O. Box 1568, 3500 BN Utrecht, The Netherlands

${ }^{\mathrm{b}}$ National Institute of Public Health and the Environment, Diagnostic Laboratory for Infectious Diseases and Screening, Bilthoven, The Netherlands

${ }^{\mathrm{c}}$ Hospices Civils de Lyon, Laboratoire de Virologie, Centre National de Référence Influenza Région-Sud, Lyon, France

${ }^{\mathrm{d}}$ Molecular Genetics of Respiratory Tract Viruses Unit, Institut Pasteur, Paris, France

e Centro Nacional de Microbiologica, Instituto de Salud Carlos III, Madrid, Spain

ABSTRACT

${ }^{\mathrm{f}}$ Radboud University Medical Center, Nijmegen, The Netherlands

Background: The increased need for accurate influenza laboratory surveillance data in the European Union required formalisation of the existing network of collaborating national influenza reference laboratories participating in the European Influenza Surveillance Scheme (EISS).

Objective: To establish a Community Network of Reference Laboratories for Human Influenza in Europe (CNRL).

Methods: Virologists in EISS defined the objective and tasks of the CNRL. Performance of the laboratories in the tasks was monitored by questionnaire-based inventories and quality control assessments (QCA). Subsequently, actions were defined to improve the performance of the CNRL.

Results: The CNRL started in April 2003 and included as of May 200432 laboratories in 24 European countries. The objective is to provide high quality reference services for human influenza surveillance, early warning and pandemic preparedness in Europe. The defined basic tasks are direct detection, culture, typing, subtyping and strain characterisation of influenza virus, diagnostic influenza serology and storage of clinical specimens and virus isolates. The questionnaire-based inventories and QCAs revealed that the majority of CNRL laboratories perform well in most of the basic tasks, although improvements are needed in certain areas of virus testing. Therefore, task groups have been established to further improve the methods used in the network. The CNRL has proven its usefulness during the 2003-2004 season by the reporting of accurate data concerning the flu epidemic caused by A/Fujian/411/2002 (H3N2)-like viruses and by the rapid sharing of information, protocols and reagents during the $\mathrm{A}(\mathrm{H} 5 \mathrm{~N} 1)$ and $\mathrm{A}(\mathrm{H} 7 \mathrm{~N} 3)$ epizootics in Asia and Canada.

Conclusion: EISS has established a functioning Community Network of Reference Laboratories for Human Influenza in Europe and laid the foundation for further enhancement and collaborations. Important next steps include improving the laboratories to carry out all basic tasks and collaboration with the European Centre for Disease Prevention and Control.

\section{INTRODUCTION}

Influenza is an important public health problem associated with increased general practice consultation rates, hospital admissions and excess death (Fleming, 2000). In addition, it must also be considered in terms of health care and influenza pandemic preparedness planning and in economic terms due to increased days lost to absence from work and school (Stephenson and Zambon, 2002).

The European Influenza Surveillance Scheme (EISS) aims to reduce the burden of disease associated with influenza in Europe by collecting and exchanging timely information on influenza activity, providing relevant information about influenza to health professionals and the general public and 
contributing to the annual determination of the influenza vaccine content and to European influenza pandemic preparedness activities (Fig. 1) (Aymard et al., 1999; Fleming et al., 2003; Manuguerra and Mosnier, 2000; Manuguerra et al., 2001; Paget et al., 2002, 2003; Zambon, 1998a).

In the pre-EISS era of influenza surveillance in Europe and in the early EISS years, laboratories in Europe were already working together, but more or less on a voluntary basis.

In 1949 the WHO established an international network of National Influenza Centres (NICs) for the surveillance of influenza (Kitler et al., 2002) and NICs in Europe have participated in this surveillance system since its creation. The predecessor of EISS was the WHO project CARE Telematics in Europe in which clinical and virological data were integrally reported (Snacken et al., 1995). The collaboration between laboratories and surveillance networks and the number of countries involved in Europe gradually increased, resulting in the establishment of EISS in 1995 (Fleming and Cohen, 1996; Fleming et al., 2003; Snacken et al., 1995, 1998). The benefits of integrated clinical and virological influenza surveillance in Europe by EISS have been described and demonstrated in the annual reports (Manuguerra and Mosnier, 2000; Manuguerra et al., 2001; Paget et al., 2002, 2003; Zambon, 1998a).

A survey on the capacities of NICs by the WHO in 2002 (World Health Organization, 2002) resulted in a program to strengthen their performance. Simultaneously, the European Commission (EC) meeting "Pandemic planning in the Community" in Brussels in 2001 highlighted the importance of EISS, the need for strengthened influenza surveillance in Europe and the need for a Community Reference Laboratory for human influenza (Commission of the European Communities, 2001). In 2002 the EISS members decided that a network of reference laboratorieswould answer the needs for strengthened influenza surveillance in the individual countries, while the allocation of specific tasks, such as the preparation and distribution of controls for virus detection, typing, subtyping and characterisation to specific laboratories within the network, would fulfil Europe-wide reference requirements.

Secondly, it was decided that the network should be coordinated from a central hub, the EISS coordination centre (EISS-CC). The necessity for the development of a Community Network of Reference Laboratories for Human Influenza in Europe coordinated by EISS has since been laid down in the EC Community Influenza Pandemic Preparedness Plan (Commission of the European Communities, 2004).

EISS launched the Community Network of Reference Laboratories for Human Influenza in Europe (CNRL) in April 2003 in Uppsala, Sweden, at the annual EISS meeting. In this paper we describe the infrastructure and tasks of the CNRL, the performance of the CNRL in these tasks and projects for the future.

\section{METHODS}

In April 2003, EISS consisted of 30 national influenza laboratories in 22 European countries which together constituted the CNRL: Belgium, the Czech Republic, Denmark, France, Germany, Ireland, Italy, Latvia, Lithuania, Luxembourg, Malta, the Netherlands, Norway, Poland, Portugal, Romania, the Slovak Republic, Slovenia, Spain, Sweden, Switzerland and the United Kingdom (England, Northern Ireland, Scotland, andWales). In May 2004, two laboratories, in Austria and Finland, were added to the CNRL. Of the 24 participating countries, 21 haveWHOrelated NICs that are partners in the CNRL. A list of all laboratories in the CNRL can be found on the EISS website (http://www.eiss.org). EISSrelated activities of the laboratories are coordinated from the EISS-CC located at the Netherlands Institute for Health Services Research (NIVEL), Utrecht, The Netherlands. The embedding of the CNRL in the EISS infrastructure is shown in Fig. 1.

Following extensive discussions between the EISS virologists, the objective and basic tasks for the CNRL were defined during the 2003 EISS annual meeting and approved at the 2004 EISS annual meeting. In 2002 and 2003, questionnaire-based inventories were performed to determine the status of the laboratories concerning the proposed basic tasks and pandemic preparedness. Two consecutive quality control assessments (QCA) carried out [ figure 1 ] in 2000 (Valette and Aymard, 2002) and 2002 were used to determine the performance of the laboratories in the proposed basic tasks. The NIC in Lyon prepared both QCA panels using methods as described previously (Valette and Aymard, 2002). Briefly, simulated respiratory specimens consisting of different amounts of a mixture of infected and non-infected cells and free virus, and negative controls containing cells only, were sent at 
a controlled temperature of $4{ }^{\circ} \mathrm{C}$ to the laboratories for analysis using their routinely used techniques for influenza surveillance. The 2000 QCA panel included 21 specimens [4 A/New Caledonia/20/99 (H1N1), 7 A/Panama/2007/99 (H3N2) (one of these contained also RSV type A), 5 B/Yamanashi/166/98, 2 RSV type A, and 3 negative controls] and the 2002 QCA panel included 15 specimens [3 A/New Caledonia/20/99 (H1N1), 1 A/Lyon/1575/02 (H1N2), 3 A/Panama/2007/99 (H3N2), 2 B/Sichuan/379/99, 2 B/Hong Kong/330/01, 2 RSV type A and 2 negative controls]. From the results, correct scores were calculated per laboratory for: (i) detection of influenza A and B virus and RSV, (ii) subtyping of influenza A virus isolates, (iii) strain characterisations of influenza A and B virus isolates and (iv) typing of RSV. The denominator for calculating the scores was defined as the number of specimens for which the specified analysis should have been carried out. Both QCAs were carried out before the CNRL was established in 2003 and laboratories participated in the QCAs on a voluntary basis. Based on the results of the inventories and QCAs, task groups were established to address specific issues to improve the performance of the CNRL.

\section{RESULTS}

\subsection{Objective and added value}

The objective of the CNRL is to provide high quality reference services for human influenza surveillance, early warning and pandemic preparedness in Europe. The accurate virological data is reported to EISS and subsequently to the European Union (EU), national health professionals and the general public (Fig. 1). The added value of the CNRL for the European Union in influenza surveillance and pandemic preparedness is: (i) Europe-wide harmonisation and standardisation of laboratory methods monitored by quality control studies, (ii) enhanced collection of information for the seasonal vaccine composition, (iii) improved early warning and reaction to (pandemic) influenza threats, (iv) rapid access to qualified persons and laboratories, (v) improved communication and exchange of information between laboratories, (vi) strengthening of the WHO network of NICs in Europe, and (vii) encouragement of Europe-wide influenza research projects and training programs.

\subsection{Basic tasks}

To guarantee comprehensive virological data reported to EISS, six basic tasks were defined that laboratories participating in the CNRL should be capable of performing. The basic tasks were based on the requirements for diagnostic virology and on the extent to which viruses should be characterised, as outlined in Table 1. The integration of the basic tasks of the CNRL in the infrastructure of EISS is shown in Fig. 1.

\subsubsection{Basic task 1: direct detection of influenza virus $A$ and $B$}

This is done by antigen detection [using immunofluorescence (IF), in-house enzyme-linked immunosorbent assay (ELISA), or commercial kits] or by genetic tests based on nucleic acid amplification techniques (NAT). Using type and/or subtype specific tests, detection, typing and/or subtyping of [ table 1 ] influenza virus in a clinical specimen can be done simultaneously.

The tests should be able to detect influenza A and B viruses when using generic techniques. When using influenzaAvirus subtype specific techniques, these tests should be able to detect at least the viruses that are currently circulating, caused previously a pandemic [e.g. A(H2N2)] or are avian viruses that caused human infection such as A(H5N1) (Chan, 2002; Claas et al., 1998; Peiris et al., 2004; Tran et al., 2004), A(H7) (Fouchier et al., 2004; Koopmans et al., 2004; ProMED-mail, 2004; Terebuh et al., 2003; Tweed et al., 2004), A(H9N2) (Guo et al., 1999; Peiris et al., 1999) and A(H10N7) (Anonymous, 2004).

\subsubsection{Basic task 2: culture of influenza virus}

Laboratories must be able to isolate and grow influenza virus. This is done using cell lines or embryonated eggs.

Growth of virus can be detected using the techniques described above and by determining the hemagglutinating activity of the culture supernatant or egg allantoic fluid.

A representative set of the isolates are sent during the season to the WHO Collaborating Centre for Reference and Research on Influenza (WHO-CC) in London that performs characterisations for CNRL 
laboratories unable to do so, confirms characterisations and compares isolates with viruses from all over the world to contribute to the WHO decision-making on the seasonal vaccine composition.

\subsubsection{Basic task 3: determination of type and subtype of influenza virus}

Laboratories must be able to type influenza virus isolates as A and B and to subtype the hemagglutinin as well as the neuraminidase of influenza A virus isolates that are currently circulating, caused previously a pandemic or are avian viruses that caused human infection (see basic task 1). Typing and subtyping can be done antigenically [e.g. by hemagglutination inhibition assay (HI) and neuraminidase inhibition assay] or genetically (by type- and subtype specific NAT). The use of the WHO identification kit using sheep antisera is recommended for the identification of isolates using HI. Sheep antisera are broad reacting and therefore only suitable for typing and subtyping and not for strain characterisation (see basic task 4). Each year, before the season starts, the WHO-CC in Atlanta, US, distributes this kit to all CNRL laboratories. The WHO-CC in Atlanta distributes also identification kits for emerging viruses, like the A(H5N1) virus, to the CNRL laboratories on request. The importance of neuraminidase subtyping was demonstrated in 2001 when an A(H1N2) virus emerged which turned out to be an A(H3N2) virus that had exchanged its hemagglutinin with that from an A(H1N1) virus (Gregory et al., 2002).

Influenza A viruses that could not be subtyped using routine techniques should be further analysed using additional techniques or send to the WHO-CC in London for further analysis.

\subsubsection{Basic task 4: strain characterisation of influenza virus}

Antigenic characterisation of the hemagglutinin is important to check the match of the seasonal vaccine with circulating viruses and for the selection of vaccine candidate viruses.

Antigenic characterisations are carried out using ferret antisera and reference virus strains distributed by the WHO-CC in London to the CNRL laboratories.

Genetic characterisation by sequencing provides important information about the genetic drift of viruses, which may directly result in antigenic alteration of the virus. Therefore, laboratories are encouraged to share sequence information with theWHO-CCin London to facilitate theWHOdecisionmaking on the seasonal vaccine composition.

\subsubsection{Basic task 5: diagnostic influenza serology}

This is carried out by using HI or the complement fixation test (CFT) and with paired sera where available. These techniques are particularly important for the retrospective analysis of outbreaks, which might take place in different countries, at a closed institution, schools, hospitals or geriatric facilities.

In addition, these techniques are important for the retrospective analysis of outbreaks that are associated with animal (particularly avian) influenza viruses being transmitted to humans during animal influenza epizootics. More sophisticated techniques such as virus neutralisation assays and subtypespecific ELISA may be introduced to enhance the sensitivity and specificity of serology.

\subsubsection{Basic task 6: storage of clinical specimens and virus isolates}

Specimens and isolates should be stored frozen at minus $80{ }^{\circ} \mathrm{C}$ for future analysis or usage.

\subsection{Other tasks}

The ability to isolate and grow influenza virus in embryonated eggs for the bi-annual selection of vaccine candidate viruses is important, but is not considered to be a basic task.

The inventory indicated that $75 \%$ of laboratories located in different regions of Europe have egg culture available, which is sufficient to secure the availability of egg-isolated viruses for vaccine candidates.

Both influenza virus and respiratory syncytial virus (RSV) are a major cause of morbidity and mortality in humans (Fleming and Cross, 1993; Zambon et al., 2001). Because influenza virus and RSV often circulate at the same time of the year and cause similar clinical symptoms, detection of both viruses is needed to differentiate their relative contribution to influenza-like-illness (ILI) and acute-respiratory-infections (ARI) (Fleming and Cross, 1993; Zambon et al., 2001). 
Although RSV detection is not yet a basic task, laboratories in the CNRL are encouraged to support the surveillance of ILI/ARI by using appropriate methods to differentiate between influenza virus and RSV in specimens taken from ILI/ARI cases. Thirteen networks perform RSV detection, as has been previously reported (Meerhoff et al., 2004).

\subsection{Status of basic tasks}

In 2002 an inventory of the methods used in the laboratories was carried out (Meerhoff et al., 2004) which was further extended in 2003 to determine the status of the laboratories concerning the basic tasks and pandemic preparedness.

Because the laboratories are continuously improving their capacities, the information was updated to the situation at December 2004 where appropriate. The overall results are shown in Table 2. Detection, culture, typing and subtyping of influenza $\mathrm{A}$ and $\mathrm{B}$ and serology were well covered.

Of the avian viruses, detection of $\mathrm{A}(\mathrm{H} 5)$ and $\mathrm{A}(\mathrm{H} 7)$ viruses were well covered, they could be detected in 79 and $71 \%$ of the 24 countries participating in EISS and by 72 and $63 \%$ of the 32 laboratories respectively. However, detection of A(H9) and A(H10) viruses was less well covered, only 31 and $19 \%$ of the laboratories respectively. Antigenic characterisations were carried out by $53 \%$ of the laboratories and in 38\% of the laboratories genetic characterisations were car- [ table 2 ] ried out. Twenty-five laboratories reported class 3 BioSafety Laboratory (BSL-3) facilities required for handling highly pathogenic viruses and two reported that they are developing these facilities.

\subsection{Quality control assessment}

To ensure accurate virological data, EISS implements obligatory QCAs for CNRL laboratories for detection, typing, subtyping and characterisation of influenza virus. CNRL laboratories should be capable of performing the basic tasks and should have a correct score of at least $90 \%$ for the basic tasks in the QCAs. This requirement will be gradually implemented.

The voluntary QCAs carried out in 2000 (Valette and Aymard, 2002) and 2002, of which the results are presented in Tables 3 and 4, are the foundation for future CNRL QCAs. When applying the requirement criteria for CNRL laboratories on the 2000 and 2002 QCAs, the proportion of laboratories with a correct score of $\geq 90 \%$ was similar for detection ( 73 and $76 \%$ respectively), but increased considerably for characterisation (50 and 93\% respectively) (Table 3).

Most notably was the increase in $100 \%$ correct score for detection (27 and $71 \%$ respectively), subtyping (36 and 79\% respectively) and characterisation (50 and 86\% respectively).

A similar observation was made for the laboratories participating in both QCAs (Table 4).

\subsection{Task groups}

Based on the results of the inventories and the results of the QCAs five task groups were established to further enhance the performance of the CNRL. The task group themes are:

(1) "Virus isolation", aiming at standardisation of cell culture, making available batches of approved cells to all laboratories and ensuring the availability of egg-isolated viruses for vaccine development.

(2) "Antibodies", aiming at standardisation of methods making use of antibodies. These include standardisation of the type of red blood cells used in the hemagglutination and hemagglutination inhibition assay, standardisation of monoclonal and polyclonal antibodies used for ELISA and IF and ensuring the availability of up-to-date sera and virus reference strains for identification and characterisation of influenza virus isolates.

(3) "Molecular virology", aiming at standardisation of methods for molecular detection of viruses and sharing of nucleic acid and amino acid sequence information among the laboratories. Tasks include development and distribution of controls for detection of hemagglutinin and neuraminidase sequences, sequencing of vaccine, prototype and early virus strains, sharing of primer, probe, and control plasmid sequences and development of an influenza sequence database for easy sharing of sequences.

(4) "Quality control assessment", aiming at the continued development and execution of QCAs for the basic tasks [ table 3 ] ried out. Twenty-five laboratories reported class 3 BioSafety Laboratory (BSL-3) facilities required for handling highly pathogenic viruses and two reported that they are developing these facilities. 


\subsection{Quality control assessment}

To ensure accurate virological data, EISS implements obligatory QCAs for CNRL laboratories for detection, typing, subtyping and characterisation of influenza virus. CNRL laboratories should be capable of performing the basic tasks and should have a correct score of at least $90 \%$ for the basic tasks in the QCAs. This requirement will be gradually implemented.

The voluntary QCAs carried out in 2000 (Valette and Aymard, 2002) and 2002, of which the results are presented in Tables 3 and 4, are the foundation for future CNRL QCAs. When applying the requirement criteria for CNRL laboratories on the 2000 and 2002 QCAs, the proportion of laboratories with a correct score of $\geq 90 \%$ was similar for detection (73 and $76 \%$ respectively), but increased considerably for characterisation (50 and 93\% respectively) (Table 3).

Most notably was the increase in $100 \%$ correct score for detection (27 and $71 \%$ respectively), subtyping (36 and 79\% respectively) and characterisation (50 and $86 \%$ respectively).

A similar observation was made for the laboratories participating in both QCAs (Table 4).

\subsection{Task groups}

Based on the results of the inventories and the results of the QCAs five task groups were established to further enhance the performance of the CNRL. The task group themes are:

(1) "Virus isolation", aiming at standardisation of cell culture, making available batches of approved cells to all laboratories and ensuring the availability of egg-isolated viruses for vaccine development.

(2) “Antibodies", aiming at standardisation of methods making use of antibodies. These include standardisation of the type of red blood cells used in the hemagglutination and hemagglutination inhibition assay, standardisation of monoclonal and polyclonal antibodies used for ELISA and IF and ensuring the availability of up-to-date sera and virus reference strains for identification and characterisation of influenza virus isolates.

(3) "Molecular virology", aiming at standardisation of methods for molecular detection of viruses and sharing of nucleic acid and amino acid sequence information among the laboratories. Tasks include development and distribution of controls for detection of hemagglutinin and neuraminidase sequences, sequencing of vaccine, prototype and early virus strains, sharing of primer, probe, and control plasmid sequences and development of an influenza sequence database for easy sharing of sequences.

(4) "Quality control assessment", aiming at the continued development and execution of QCAs for the basic tasks [ table 4 ] including the EISS-CC, the advantages overrule the possible disadvantages.

The European Commission supports the CNRL by covering costs for coordination, meetings and database facilities, while the activities of the participating laboratories are mainly funded by the respective national governments, as indicated by a WHO survey (World Health Organization, 2002). Additional funds come from institutes, universities and donor agencies (World Health Organization, 2002). However, these funds do not cover the overhead laboratory costs for adequate generation, control, storage and distribution of standardised reagents for the surveillance of seasonal and emerging influenza viruses, nor the costs for research projects needed to improve the surveillance and preparedness activities or for annual QCAs. One of the aims of EISS is to raise additional funds to cover these costs.

The basic tasks defined for theCNRLare slightly more extensive than described in the WHO terms of reference for the NICs, in which less well-equipped laboratories in developing countries must be taken into account (World Health Organization, 2002, 2005b). The inventory of the basic tasks indicates that most CNRL laboratories are capable of performing most tasks, but that improvements are required in the ability to subtype avian influenza viruses and in the ability to characterise viruses both antigenically and genetically. Some laboratories reported not having the human and/or equipment resources to fulfil the requirement of performing all basic tasks thatCNRL laboratories should be capable of. In addition, the 2002 QCA showed that some laboratories need to improve their performance in carrying out the basic tasks, as they did not meet the criterion of $\geq 90 \%$ correct score on all basic tasks that will be implemented for CNRL laboratories (Table 3). One solution for those laboratories may be to organise regional facilities to achieve the requirements, as currently occurs for laboratories that do not have the resources to perform antigenic and genetic characterisations that send 
isolates to the WHO-CC in London. Also, the EISS-CC may offer assistance; e.g. during the epizootics of A(H5N1) in Asia in 2003 and 2004 (Peiris et al., 2004;Tran et al., 2004) and of A(H7N3) in Canada in 2003 (Tweed et al., 2004), the EISS-CC collected and facilitated the distribution of hemagglutininRNAsequence information, protocols and control material to the CNRL, in collaboration with the WHO-CC in London. In addition, to improve the preparedness of the CNRL for detection of animal influenza viruses that could potentially cause a pandemic collaboration has been sought with the Community Reference Laboratory for Avian Influenza in Europe at the Veterinary Laboratories Agency,Weybridge, UK. Finally, the EISS-CC implemented a structural approach to improve the performance of basic tasks in the CNRL by the installation of five thematic task groups that will address specific issues.

Appropriate biosafety precautions should be available at the laboratory to handle clinical specimens suspected of containing avian influenza viruses and towork with these viruses, especially the highly pathogenic viruses (World Health Organization, 2005a; Zambon, 1998b). Although detection of those viruses in clinical specimens by NAT can be carried out in a class 2 BioSafety Laboratory (BSL-2) (World Health Organization, 2005a), isolation and growing of the avian viruses and holding live control material require dedicated BSL-3 facilities (World Health Organization, 2005a) and an appropriate permit from the country's government to handle and hold such materials. The virological inventory indicated that most countries have a BSL-3 facility, and other countries have plans for such a laboratory, demonstrating that the CNRL is partially prepared for a pandemic derived from an avian virus strain.

The CNRL functioned well in routine surveillance with enhanced data entry, including the possibility of adaptation of the database to emerging viruses. This is exemplified by the reporting of accurate data to the public via the website and to the EC during the 2003-2004 season (Paget et al., 2005), proving the added value of the network. This was particularly important as the 2003-2004 seasonal influenza epidemic was caused by A/Fujian/411/2002 (H3N2)-like viruses that are drift-variants of the A/Panama/2007/99 (H3N2) strain included in the 2003-2004 vaccine and concerns were raised about the effectiveness of the vaccine against this circulating mismatched virus (CDC, 2004).

Increased usage of antiviral drugs for therapy and (postexposure) prevention of influenza and stockpiling of these drugs for pandemic preparedness require a clear understanding of their effects and possible drawbacks, such as the development of resistance (Kiso et al., 2004). Therefore, EISS established a task group to address this issue in collaboration with the VIRGIL project. A project to implement the recording of weekly data on the usage of antiviral drugs and number of resistant isolates and of sequence data of resistant isolates is planned in 2005.

In conclusion, EISS has built, with the support and efforts of contributing laboratories, a Community Network of Reference Laboratories for Human Influenza in Europe. This network is functioning in seasonal influenza surveillance, early warning and pandemic preparedness, in collaboration with the clinical partners within EISS. The foundation for further enhancement and collaborations has been laid. The next steps include further improving the ability of laboratories to carry out all basic tasks, harmonisation and standardisation of diagnostic methods, initiation and participation in research projects such as that for developing a network of excellence for antiviral resistance (VIRGIL), development of new databases, enhanced collaboration with the WHO and the new European Centre for Disease Prevention and Control (ECDC) (Kokki and Haigh, 2004) and integration of a pandemic preparedness plan in CNRL activities.

\section{ACKNOWLEDGEMENTS}

EISS is primarily funded by the Health and Consumer Protection Directorate-General of the European Commission.

All participating sentinel physicians, epidemiological institutes and laboratories across Europe are greatly acknowledged for their ongoing support and contribution to EISS and the CNRL. Paul Taylor, Quad Logic, Paris, is acknowledged for developing and maintaining the EISS databases and website.

\section{TABLES AND FIGURES}


A. Meijer, M. Valette, J.C. Manuguerra, P. Perez-Brena, J. Paget, C. Brown, K. van der Velden Implementation of the community network of reference laboratories for human influenza in Europe. Journal of Clinical Virology: jrg. 34, 2005, nr. 1, p. 87-96

Table 1

Relationship between clinical specimen, virus architecture, diagnostic techniques, extent of virus characterisation and basic tasks of the Community Network of Reference Laboratories for Human Influenza in Europe (CNRL)

\begin{tabular}{|c|c|c|c|c|c|}
\hline \multirow[t]{3}{*}{ Patient / Specimen } & \multirow[t]{3}{*}{ Component } & \multicolumn{4}{|c|}{$\begin{array}{l}\text { Extent of virus characterisation by } \\
\text { diagnostic method a }\end{array}$} \\
\hline & & \multirow{2}{*}{$\underset{\text { virus }}{\text { Influenza }}$} & Influenza A virus & $\begin{array}{c}\mathrm{H} / \mathrm{N} \text { subtype } \\
(\mathrm{H} 1-\mathrm{H} 16 / \mathrm{N} 1-\mathrm{N} 9)\end{array}$ & $\begin{array}{l}\text { Strain, e.g. } \\
\text { A/Wellington/1/2004 (H3N2) }\end{array}$ \\
\hline & & & Influenza B virus & Influenza B virus & $\begin{array}{c}\text { Strain, e.g. } \\
\text { B/Jiangsu/10/2003 }\end{array}$ \\
\hline \multirow{4}{*}{ Influenza virus particle } & $\begin{array}{l}\text { Antigen } \\
- \text { Nucleoprotein } \\
- \text { Hemagglutinin } \\
\end{array}$ & $\mathrm{HA}$ & IF, ELISA & $\begin{array}{c}\mathrm{HI} \text { (sheep sera), IF } \\
\mathrm{NI}\end{array}$ & $\mathrm{HI}$ (ferret sera) \\
\hline & Infectious virus & Isolation & & & \\
\hline & $\begin{array}{l}\text { RNA } \\
\text { - Matrix } \\
\text { - Neuraminidase } \\
\end{array}$ & 1 & NAT & $\begin{array}{l}\text { NAT } \\
\text { NAT }\end{array}$ & $\begin{array}{l}\text { Sequencing } \\
\text { Sequencing }\end{array}$ \\
\hline & Antibodies & & $\mathrm{HI}, \mathrm{CFT}, \mathrm{ELISA}$ & HI, ELISA, VN & \\
\hline Basic task CNRL b & & 2,6 & $1,3,5$ & $1,3,5$ & 4 \\
\hline
\end{tabular}

${ }^{a} \mathrm{HA}$, hemagglutination assay; IF, immunofluorescence; ELISA, enzyme-linked immunosorbent assay; HI, hemagglutination inhibition assay; NI, neuraminidase inhibition assay; NAT, nucleic acid amplification techniques; CFT, complement fixation test; VN, virus neutralisation assay. ${ }^{b}$ Basic tasks: (1) direct detection; (2) culture; (3) typing and subtyping; (4) strain characterisation; (5) diagnostic influenza serology and (6) storage of clinical specimens and virus isolates. 
A. Meijer, M. Valette, J.C. Manuguerra, P. Perez-Brena, J. Paget, C. Brown, K. van der Velden Implementation of the community network of reference laboratories for human influenza in Europe. Journal of Clinical Virology: jrg. 34, 2005, nr. 1, p. 87-96

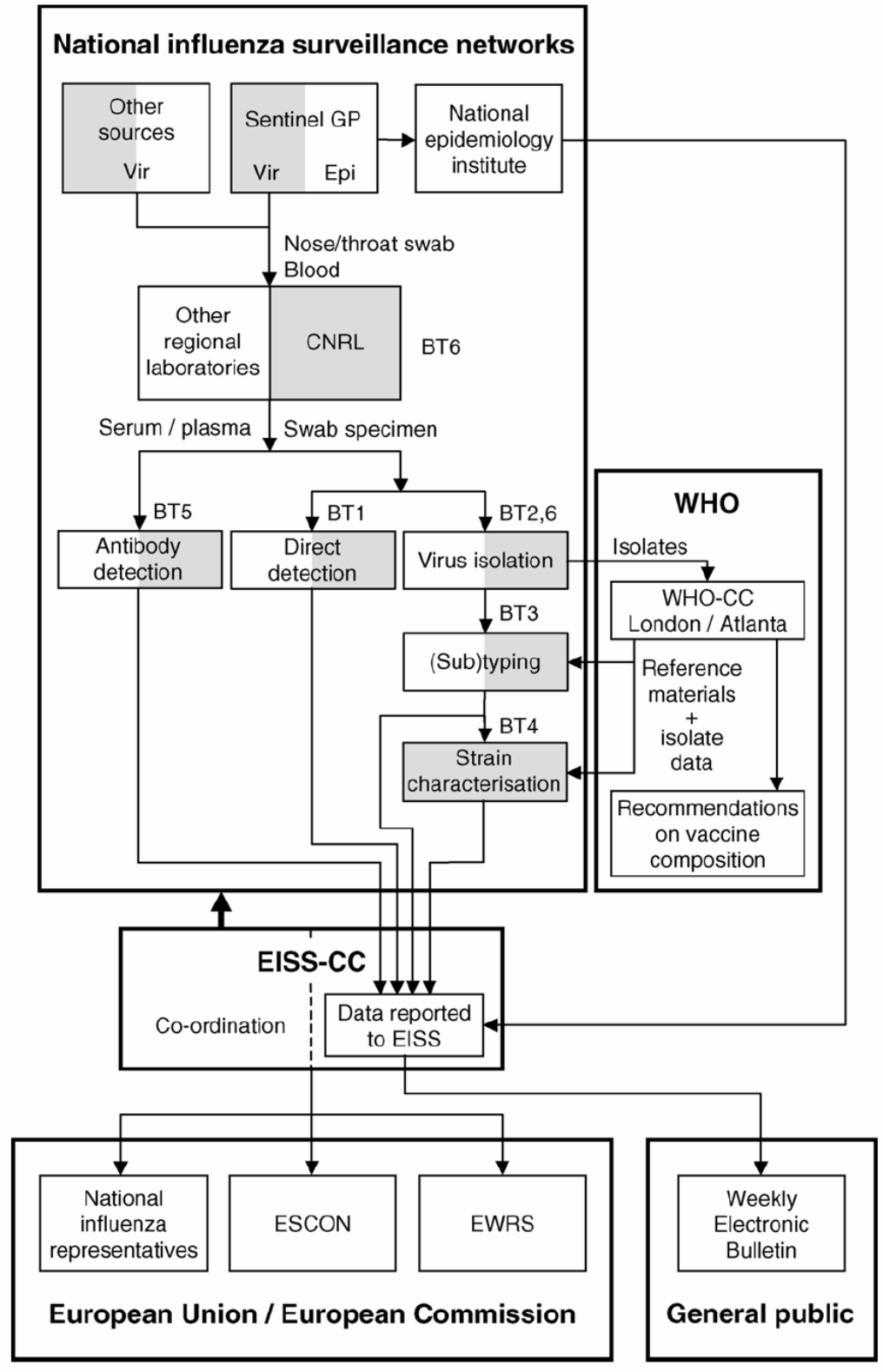

Fig. 1. Infrastructure and information flow of the European Influenza Surveillance Scheme (EISS). Basic task activities of the Community Network of Reference Laboratories for Human Influenza in Europe (CNRL) are grey shaded. Vir, virological specimens; Epi, epidemiological influenza surveillance data; GP, general practitioner; BT, basic task (see Section 3); WHO, World Health Organisation; WHO-CC, WHO Collaborating Centre for Reference and Research on Influenza; EISS-CC, European Influenza Surveillance Scheme co-ordination centre; ESCON, European Union Epidemiological Surveillance Component of the Community Network; EWRS, European Union Early Warning and Response System. 
A. Meijer, M. Valette, J.C. Manuguerra, P. Perez-Brena, J. Paget, C. Brown, K. van der Velden Implementation of the community network of reference laboratories for human influenza in Europe. Journal of Clinical Virology: jrg. 34, 2005, nr. 1, p. 87-96

Table 2

Inventory of laboratories in the CNRL capable of performing the required basic tasks

\begin{tabular}{|c|c|}
\hline Task & $\begin{array}{l}\text { Number of laboratories } \\
\text { capable of performing a } \\
\text { basic task }(N=32)^{\mathrm{a}}\end{array}$ \\
\hline 1. Direct detection (influenza A and B) & $31(97 \%)^{b}$ \\
\hline 2. Culture (cell and/or egg) & $30(94 \%)$ \\
\hline Cell & $30(94 \%)$ \\
\hline Egg (routine) & $10(31 \%)$ \\
\hline 3a. Typing (influenza A and B) & $32(100 \%)^{b}$ \\
\hline \multicolumn{2}{|l|}{ 3b. Subtyping } \\
\hline H1 & $29(91 \%)$ \\
\hline $\mathrm{H} 2$ & $12(38 \%)$ \\
\hline $\mathrm{H} 3$ & $29(91 \%)$ \\
\hline $\mathrm{H} 5^{\mathrm{c}}$ & $23(72 \%)$ \\
\hline $\mathrm{H} 7^{\mathrm{c}}$ & $20(63 \%)$ \\
\hline H9 & $10(31 \%)$ \\
\hline $\mathrm{H} 10$ & $6(19 \%)$ \\
\hline N1 & $20(63 \%)$ \\
\hline N2 & $21(66 \%)$ \\
\hline N3 & $5(16 \%)$ \\
\hline N7 & $6(19 \%)$ \\
\hline \multicolumn{2}{|l|}{ 4. Characterisation (drift analysis) ${ }^{\mathrm{d}}$} \\
\hline Antigenic & $17(53 \%)$ \\
\hline Genetic & $12(38 \%)$ \\
\hline 5. Serology & $30(94 \%)$ \\
\hline 6. Storage & No inventory made \\
\hline \multicolumn{2}{|c|}{$\begin{array}{l}\text { a Data retrieved from the virological questionnaire sent in } 2003 \text { and up } \\
\text { dated to the situation at December } 2004 \text {. } \\
\text { b One is currently developing the laboratory and uses only serology fo } \\
\text { influenza diagnosis. } \\
\text { c Twenty-five laboratories have BioSafety Level } 3 \text { (BSL-3) facilities to } \\
\text { handle Highly Pathogenic Avian Influenza viruses that could infect humans } \\
\text { In addition, two laboratories are developing a BSL-3 facility. } \\
{ }^{d} \text { In addition, all laboratories are requested to send representative subset } \\
\text { of viruses to the WHO Collaboration Centre for Reference and Research or } \\
\text { Influenza, Mill Hill, London, for (further) characterisation. }\end{array}$} \\
\hline
\end{tabular}

Table 3

Result of laboratories in the $2000^{\mathrm{a}}$ and 2002 QCAs for detection of influenza A and B virus and respiratory syncytial virus (RSV), subtyping of influenza A virus, strain characterisation of influenza virus and typing of RSV

\begin{tabular}{llll}
\hline Type of analysis & Correct score (\%) & \multicolumn{2}{l}{ Number of laboratories in year (total correct/total performing) } \\
\cline { 3 - 4 } & & 2000 & 2002 \\
\hline Detection influenza A and B virus and RSV & $\geq 90$ & $11 / 15(73 \%)$ & $16 / 21(76 \%)$ \\
Subtyping influenza A virus & 100 & $4 / 15(27 \%)$ & $15 / 21(71 \%)$ \\
& $\geq 90$ & $11 / 14(79 \%)$ & n.a. \\
Strain characterisation influenza virus & 100 & $5 / 14(36 \%)$ & $15 / 19(79 \%)$ \\
& $\geq 90$ & $3 / 6(50 \%)$ & $13 / 14(93 \%)$ \\
Typing RSV & 100 & $3 / 6(50 \%)$ & $12 / 14(86 \%)$ \\
\hline
\end{tabular}

a QCA 2000 (Valette and Aymard, 2002).

${ }^{b}$ n.a. $=$ not applicable, as the number of specimens (7) was too low to distinguish between $\geq 90$ and $100 \%$ correct score.

c A correct score of $\geq 90 \%$ was not used as the number of specimens containing RSV was too low to distinguish between $\geq 90$ and $100 \%$ correct score. 
A. Meijer, M. Valette, J.C. Manuguerra, P. Perez-Brena, J. Paget, C. Brown, K. van der Velden Implementation of the community network of reference laboratories for human influenza in Europe. Journal of Clinical Virology: jrg. 34, 2005, nr. 1, p. 87-96

\begin{tabular}{|c|c|c|c|}
\hline \multirow[t]{2}{*}{ Type of analysis } & \multirow[t]{2}{*}{ Correct score (\%) } & \multicolumn{2}{|c|}{ Number of laboratories in year (total correct/total performing) } \\
\hline & & 2000 & 2002 \\
\hline Detection influenza A and B virus and RSV & $\begin{array}{l}\geq 90 \\
100\end{array}$ & $\begin{array}{l}10 / 14(71 \%) \\
4 / 14(29 \%)\end{array}$ & $\begin{array}{l}11 / 14(79 \%) \\
10 / 14(71 \%)\end{array}$ \\
\hline Subtyping influenza A virus & $\begin{array}{l}\geq 90 \\
100\end{array}$ & $\begin{array}{l}11 / 13(85 \%) \\
5 / 13(38 \%)\end{array}$ & $\begin{array}{l}\text { n.a. }{ }^{\mathrm{b}} \\
12 / 14(86 \%)\end{array}$ \\
\hline Strain characterisation influenza virus & $\begin{array}{l}\geq 90 \\
100\end{array}$ & $\begin{array}{l}3 / 5(60 \%) \\
3 / 5(60 \%)\end{array}$ & $\begin{array}{l}10 / 10(100 \%) \\
9 / 10(90 \%)\end{array}$ \\
\hline Typing RSV ${ }^{c}$ & 100 & $5 / 5(100 \%)$ & $7 / 7(100 \%)$ \\
\hline
\end{tabular}

\section{REFERENCES}

1. Anonymous. Avian Influenza Virus $A(H 10 N 7)$ Circulating among Humans in Egypt. EID Weekly Updates: Emerging and Reemerging Infectious Diseases, Region of the Americas, vol. 2, no. 18-7, May 2004. Available from: http://www.paho.org/english/AD/DPC/CD/eideer- 07-may-2004.htm.

2. Aymard $M$, Valette $M$, Lina $B$, Thouvenot $D$. Surveillance and impact of influenza in Europe. Groupe Regional d'Observation de la Grippe and European Influenza Surveillance Scheme. Vaccine 1999;17(Suppl 1):S30-41.

3. CDC. Preliminary assessment of the effectiveness of the 2003-2004 inactivated influenza vaccine, Colorado, December 2003. MMWR 2004;53:8-11.

4. CDC. Overview of Influenza Surveillance in the United States. CDC, Atlanta, US. 2 February 2005. Available from: http://www.cdc.gov/flu/weekly/pdf/flu-surveillance-overview.pdf.

5. Chan PK. Outbreak of avian influenza A(H5N1) virus infection in Hong Kong in 1997. Clin Infect Dis 2002;34(Suppl 2):S58-64.

6. Claas EC, Osterhaus AD, van Beek R, De Jong JC, Rimmelzwaan GF, Senne DA, et al. Human influenza A H5N1 virus related to a highly pathogenic avian influenza virus. Lancet 1998;351:472477 (Erratum in: Lancet 1998;351:1292).

7. Commission of the European Communities. Preliminary Conclusions and Recommendations. Preparedness planning in the community: Influenza and other health threats. Brussels: Commission of the European Communities; 27 November 2001. Available from: http://europa.eu.int/comm/health/ph threats/com/Influenza/conclusion en.pdf.

8. Commission of the European Communities. Commission Working Paper on Community Influenza Pandemic Preparedness and Response Planning. Brussels: Commission of the European Communities; 26 March 2004. Available from: http://europa.eu.int/comm/ health/ph threats/com/Influenza/com 2004201 en.pdf.

9. Fleming DM, Cross KW. Respiratory syncytial virus or influenza? Lancet 1993;342:1507-10.

10. Fleming DM, Cohen JM. Experience of European collaboration in influenza surveillance in the winter of 1993-1994. J Public Health Med 1996;18:133-42.

11. Fleming DM. The contribution of influenza to combined acute respiratory infections, hospital admissions, and death in winter. Commun Dis Public Health 2000;3:32-8.

12. Fleming DM, van der Velden J, Paget WJ. The evolution of influenza surveillance in Europe and prospects for the next 10 years. Vaccine 2003;21:1749-53.

13. Fouchier RA, Schneeberger PM, Rozendaal FW, Broekman JM, Kemink SA, Munster V, et al. Avian influenza A virus (H7N7) associated with human conjunctivitis and a fatal case of acute respiratory distress syndrome. Proc Natl Acad Sci USA 2004;101:1356-61.

14. Gregory V, Bennett M, Orkhan MH, Al Hajjar S, Varsano N, Mendelson E, et al. Emergence of influenza A H1N2 reassortant viruses in the human population during 2001. Virology 2002;300:17.

15. Guo Y, Li J, Cheng X. Discovery of men infected by avian influenza A (H9N2) virus. Chin J Exp Clin Virol 1999;13:105-8 (in Chinese).

16. Kitler ME, Gavinio P, Lavanchy D. Influenza and the work of the World Health Organization. Vaccine 2002;20(Suppl 2):S5-14. 
A. Meijer, M. Valette, J.C. Manuguerra, P. Perez-Brena, J. Paget, C. Brown, K. van der Velden Implementation of the community network of reference laboratories for human influenza in Europe.

Journal of Clinical Virology: jrg. 34, 2005, nr. 1, p. 87-96

17. Kiso M, Mitamura K, Sakai-Tagawa Y, Shiraishi K, Kawakami C, Kimura K, et al. Resistant influenza A viruses in children treated with oseltamivir: descriptive study. Lancet 2004;364:75965.

18. Kokki M, Haigh R. Perspectives for a European Centre for Disease Prevention and Control. Eur Surveill 2004;9:3-4.

19. Koopmans M, Wilbrink B, Conyn M, Natrop G, van der Nat H, Vennema H, et al. Transmission of H7N7 avian influenza A virus to human beings during a large outbreak in commercial poultry farms in the Netherlands. Lancet 2004;363:587-93.

20. Macey JF, Winchester B, Squires SG, Tam T, Zabchuk P, Li Y. Respiratory virus surveillance. FluWatch project, 2000-2001. End of season update. Can Commun Dis Rep 2001;27:96-100.

21. Manuguerra JC, Mosnier A. Surveillance of influenza in Europe from October 1999 to February 2000. Eur Surveill 2000;5:63-8.

22. Manuguerra JC, Mosnier A, Paget WJ. EISS (European Influenza Surveillance Scheme). Monitoring of influenza in the EISS European network member countries from October 2000 to April 2001. Eur Surveill 2001;6:127-35.

23. Meerhoff TJ, Meijer A, Paget WJ. EISS. Methods for sentinel virological surveillance of influenza in Europe-an 18-country survey. Eur Surveill 2004;9:1-4.

24. Paget WJ, Meerhoff TJ, Goddard NL. EISS. Mild to moderate influenza activity in Europe and the detection of novel $A(H 1 N 2)$ and $B$ viruses during the winter of 2001-2002. Eur Surveill 2002;7:147-57.

25. Paget WJ, Meerhoff TJ, Rebelo de Andrade H. EISS. Heterogeneous influenza activity across Europe during the winter of 2002-2003. Eur Surveill 2003;8:230-9.

26. Paget J, Meerhoff T, Meijer A. Epidemiological and virological assessment of influenza activity in Europe during the 2003-2004 season, Euro Surveill 2005, in press.

27. Peiris M, Yuen KY, Leung CW, Chan KH, Ip PL, Lai RW, et al. Human infection with influenza H9N2. Lancet 1999;354:916-7.

28. Peiris JS, Yu WC, Leung CW, Cheung CY, Ng WF, Nicholls JM, et al. Re-emergence of fatal human influenza A subtype H5N1 disease.Lancet 2004;363:617-9.ProMED-mail. Avian influenza A(H7N2) virus, human-USA (New York). ProMED-mail 2004; 20 Apr: 20040420.1104. http://www.promedmail.org/ (accessed 5 November 2004).

29. Snacken R, Bensadon M, Strauss A. The CARE telematics network for the surveillance of influenza in Europe. Meth Inf Med 1995;34:518- 22.

30. Snacken R, Manuguerra JC, Taylor P. European Influenza Surveillance Scheme on the Internet. Meth Inf Med 1998;37:266-70.

31. Stephenson I, Zambon M. The epidemiology of influenza. Occup Med 2002;52:241-7.

32. Terebuh P, Adija A, Katz J, Jenkins S, Edwards L, Kleene J, et al. Abstract. Title: Human infection with avian influenza A(H7N2)-United States, 2002. Options for the Control of Influenza V., abstr.W01P-72.

33. Tran TH, Nguyen TL, Nguyen TD, Luong TS, Pham PM, Nguyen VC, et al. World Health Organization International Avian Influenza Investigative Team. Avian influenza A (H5N1) in 10 patients in Vietnam. N Engl J Med 2004;350:1179-88.

34. Tweed SA, Skowronski DM, David ST, Larder A, Petric M, Lees M, et al. Human illness from avian influenza H7N3, British Columbia. Emerg Infect Dis 2004;10:2196-9.

35. Valette M, Aymard M. Quality control assessment of influenza and RSV testing in Europe: 20002001 season. Eur Surveill 2002;7:161-5.

36. World Health Organization. WHO Global Influenza Programme: survey on capacities of national influenza centres, January-June 2002. Weekly Epidemiological Record 2002;77:350-6.

37. World Health Organization. WHO Communicable Disease Surveillance \& Response. WHO laboratory biosafety guidelines for handling specimens suspected of containing avian influenza $A$ virus, 12 January 2005a. Available from: http://www.who.int/entity/csr/disease/ avian influenza/guidelines/handlingspecimens/en.

38. World Health Organization. WHO Global Influenza Programme: Terms of reference for National Influenza Centres [cited 5 February 2005b]. Available from: http://www.who.int/csr/disease/influenza/en/ TORNICs.pdf.

39. Yohannes K, Roche P, Hampson A, Miller M, Spencer J. Annual report of the National Influenza Surveillance Scheme, 2003. Commun Dis Intell 2004;28:160-8.

40. Zambon M. Sentinel surveillance of influenza in Europe 1997-1998. Eur Surveill 1998a;3:29-31.

41. Zambon M. Laboratory containment for influenza A H5N1 virus: level 2, level 3, or level 3+? Commun Dis Public Health 1998b;1:71-2. 
A. Meijer, M. Valette, J.C. Manuguerra, P. Perez-Brena, J. Paget, C. Brown, K. van der Velden Implementation of the community network of reference laboratories for human influenza in Europe. Journal of Clinical Virology: jrg. 34, 2005, nr. 1, p. 87-96

42. Zambon MC, Stockton JD, Clewley JP, Fleming DM. Contribution of influenza and respiratory syncytial virus to community cases of influenza- like illness: an observational study. Lancet 2001;358:1410-6. 